\title{
Analysis of Motor Activities of Professional Soccer Players during the 2014 World Cup in Brazil
}

\author{
by \\ Paweł Chmura1, Marcin Andrzejewski², Marek Konefat ${ }^{3}$, Dariusz Mroczek ${ }^{3}$, \\ Andrzej Rokita ${ }^{1}$, Jan Chmura ${ }^{3}$
}

The aim of the present study was to analyze motor activities of soccer players in seven consecutive rounds of matches of the 2014 World Cup in Brazil and to compare the performance of the world champions, the German national team with other participating teams. The study sample comprised 905 observations of 340 soccer players, who played full-time matches in all seven rounds of the tournament. The study was conducted using data collected from the Castrol Performance Index, a kinematic game analysis system that records movements of players with semi-automatic cameras. The following variables were analyzed: total distance covered, the percentage of total distance covered at high intensity, the number of sprints, frequency of sprints and peak running speed. A statistically significant increase $(p \leq 0.01)$ was noted in total distance covered, the percentage of distance covered at high intensity and total number of sprints, between the quarter-finals and semi-finals of the World Cup tournament in Brazil. The German national team covered a significantly longer total distance $(p \leq 0.05)$ and had a greater percentage of distance covered at high intensity $(p \leq$ 0.001) than players from other teams. The obtained results point to the necessity of development of players' aerobic endurance and speed-endurance abilities while preparing for top-level soccer tournaments. Winning a soccer championship requires players to run longer mean total distances and longer distances at high intensity during a single match.

Key words: match analysis, group stage, knockout stage, distance covered, sprints, World Champion.

\section{Introduction}

Modern soccer is characterized by increasingly high dynamics and the number of direct one-on-one plays, players' excellent motor and mental preparation as well as technicaltactical skills (Bangsbo and Krustrup, 2008). In top-level soccer tournaments, a team reaching the final plays seven matches in a month. Maintaining top performance throughout a tournament requires from players a high level of aerobic endurance, speed and strength (Hoff and Helgerud, 2004). From the physiological standpoint, appropriate training load control, hydration, supplementation and regeneration of the player's body are also of great significance (Fowler et al., 2014; Kurdak et al., 2010). Reaching high sport performance in a relatively short time between the end of a competitive season and the start of the World Cup is very difficult for soccer players, who might be tired, overloaded and lack proper recovery after intensive league seasons (Reilly et al., 2008).

The acyclical character of movements, frequently changing situations and playing pace in soccer require players to generate energy from

1 - Chair of Team Sports, University School of Physical Education in Wrocław, Wrocław, Poland.

2 - Chair of Recreation, University School of Physical Education in Poznań, Poznań, Poland.

3 - Chair of Motor Skills, University School of Physical Education in Wrockaw, Wroctaw, Poland. 
different sources via the aerobic and anaerobic metabolism (Oh et al., 2011; Reilly, 2003). During a soccer game short exercises performed by players at maximal and high intensity (sprinting, striding) dominated by anaerobic energy processes are intertwined with activities of moderate and low intensity (walking, jogging) characterized by aerobic energy processes. However, match playing time, exercise intensity and the percentage of time devoted to the performance of particular activities clearly indicate that soccer match performance is dominated by the aerobic metabolism as indicated by Bangsbo (1994) and Andrzejewski et al. (2013). Low-intensity exercise and rest periods during a match, lasting from a few to more than ten seconds, are necessary for muscle relaxation, body recovery and lactate utilization (Spencer et al., 2005). A high level of players' aerobic fitness $\left(\mathrm{VO}_{2 \max }\right)$ enhances all these reactions and physiological-biochemical processes (Gharbi et al., 2015).

In soccer, a good measurement of players' exercise performance is the total distance covered in match play (collectively by a team and by individual players), consisting of distances covered when walking, jogging and running at low, moderate and high intensity in different directions. The analysis of distance covered by the teams taking part in the 2010 World Cup in South Africa showed that top national teams covered in total about $110 \mathrm{~km}$ in a single game (Oh et al., 2011), while individual world class players ran from 9.6 to $12-13.5 \mathrm{~km}$ per match (Bangsbo et al., 2009; Di Salvo et al., 2007; Djaoui et al., 2014). The covered distance may be also related to the player's position on the pitch. The longest mean distance in a match is shown to be covered by midfielders $(9.83-12.29 \mathrm{~km})$, followed by defenders $(9.57-11.41 \mathrm{~km})$ and forwards (9.6111.38 km) (Di Salvo et al., 2007; Djaoui et al., 2014; Mohr et al., 2003; Oh et al., 2011). Bishop and Girard (2013) noted that players' activity during a match increased in the last decade, which can be illustrated by the length of distance covered at high intensity. Currently, this may even amount to $25-27 \%$ of the total distance covered, depending on the accepted speed threshold (Chmura et al., 2014; Konefał et al., 2014).

The number, length and frequency of performed sprints as well as development of peak running speed are among the key manifestations of players' speed abilities. They are based on two strictly and functionally related pillars: motor and cognitive. A player's speed and effectiveness are determined by their motor skills (moving on the pitch with and without the ball) controlled by neurophysiological processes and cognitive skills (e.g. speed and accuracy of perception, anticipation, decision making and reaction) initiated and controlled by mental processes (Oh et al., 2011). Soccer players from top-level national leagues can cover sprinting distances from 152 to $446 \mathrm{~m}$, depending on their position on the field (Bradley et al., 2009; Di Salvo et al., 2007), while players from the UEFA European League teams, from 167 to $345 \mathrm{~m}$ (Andrzejewski et al., 2013). In the English and Spanish top soccer leagues the highest number of sprints per game is performed by forwards (from 12 to 16) and the lowest by defenders (from 8 to 9) (Dellal et al., 2010). It must be stressed that authors of longtime kinematic studies have used different methods and speed thresholds in defining sprints in soccer, i.e. from 6.4 to $8.3 \mathrm{~m} / \mathrm{s}$ (Andrzejewski et al., 2013; Bangsbo, 1994; Mohr et al., 2003). Dellal et al. (2011) claim that the explosive start of the run, the ability to increase speed over the covered distance and reaching peak speed are among the key components affecting players' effectiveness during a soccer match. During the 2010 World Cup in South Africa, the world champions, i.e. the Spanish national team, reached a peak running speed of $25.52 \mathrm{~km} / \mathrm{h}$ (Oh et al., 2011).

It is very difficult for soccer players to maintain their motor skills at a relatively high level for the whole duration of an international soccer tournament. Considering the available literature, soccer researchers have not studied matches of both the group and the knockout stages of a World Cup at the same time yet. From a cognitive point of view, it would be also interesting to investigate whether players from the World Cup winning team differ in terms of their levels of motor abilities from players from other participating teams. Therefore, the aim of the present study was to analyze total distance covered, the percentage of total distance covered at high intensity, total number of performed sprints and peak running speed attained by soccer players in seven consecutive rounds of matches of the 2014 World Cup in Brazil. Furthermore, the 
study also compared the performance of the German national team, the World Champion, with other teams.

\section{Material and Methods}

\section{Participants}

The research material consisted of 340 soccer players from 32 teams taking part in the 2014 World Cup in Brazil. The physical activity of all players, excluding the goalkeepers, who played for the whole duration of the match (without extra time) was analyzed. The number of such players in all 64 matches in the seven rounds of the tournament was: $n=226$ in the first matches of the group stage; $n=224$ in the second matches of the group stage; $\mathrm{n}=228$ in the third matches of the group stage; $\mathrm{n}=113$ in the Round of 16 matches; $\mathrm{n}=57$ in the quarter-finals; $\mathrm{n}=28$ in the semi-finals; and $n=29$ in the final and the third place match. The players' mean body height was $180.65 \pm 6.56 \mathrm{~cm}$, body mass $76.47 \pm 7.13 \mathrm{~kg}$ and age $27.08 \pm 3.71$ years. The players' data was taken from the FIFA website and the conduct of the study did not require any ethical approval or consent forms.

\section{Procedures}

The analysis was carried out using data gathered with the Castrol Performance Index game analysis system, to identify the length of the covered distance and various forms of players' actions during the game (Reilly, 2003). The Castrol Performance Index permits a thorough match motion analysis with semi-automatic videocameras. This highly objective system was first applied during the 2008 European Cup.

The data gathering by the system is a complex process which includes the placement of two sets of four cameras in a soccer stadium allowing simultaneous tracking of the players' actions during each second of the game and in all sections of the soccer pitch. The Castrol Performance Index enables match analysis in real time by gathering information from the cameras recording images at the speed of 25 frames per second. The system can measure the following variables: a) players' positions at any moment of the game; b) players' and ball speed; c) covered distance; d) team formation on the field by individual players; e) relations between players (Soroka, 2014). Each recorded movement by a player on the pitch is computer-processed into quantitative data. Thus, the system provides data on the course of the player's match performance, its volume and intensity, types of movements and forms of their execution as well as selected soccer skills (Di Salvo et al., 2009).

The study analyzed the following variables (recorded during match-play, excluding extra time): total distance covered $[\mathrm{km}]$; the percentage of total distance covered at high running intensity, from 19.9 to $25.2 \mathrm{~km} / \mathrm{h}$ [\%], total number of sprints above the speed of $25.2 \mathrm{~km} / \mathrm{h}$ [number]; frequency of sprints [match play in s/number of sprints]; and peak running speed $[\mathrm{km} / \mathrm{h}]$. Differences in the variables between seven consecutive rounds of matches of the World Cup tournament i.e. three rounds of the group stage and four rounds of the knockout stage, were analyzed. Also a comparison was made between the players of the champion German team and players from other teams participating in the 2014 World Cup in Brazil.

\section{Statistical Analysis}

All statistical calculations were made using the Statistica software package (ver. 12.0). The conformity with normal distribution of all variables was checked with the Shapiro-Wilk test $(p<0.05)$. Arithmetic means and standard deviations as well as the minimum and maximum values were calculated. To compare the mean values of the examined variables between the seven consecutive rounds of matches a one-way analysis of variance was used, and to determine the differences between the world champion team and other teams, a t-test for independent samples was applied. The differences between the pairs of means were checked with the Fisher's Least Significant Difference (LSD) test. The levels of significance were set at $p \leq 0.05, \mathrm{p} \leq 0.01$ and $p \leq$ 0.001 .

\section{Results}

\section{Covered distance}

The study results revealed that all players taking part in the 2014 World Cup in Brazil covered a mean distance of $10.07 \pm 0.96 \mathrm{~km}$ per match. As far as the measured distance in the seven consecutive rounds of the tournament is concerned, the total distance covered by players in the three matches of the group stage was relatively stable (Figure 1). In the Round of 16, total distance covered was significantly shorter 
$(p \leq 0.001)$. Between the quarter-finals $(9.74 \pm 0.78$ $\mathrm{km})$ and semifinals $(10.38 \pm 0.98)$, the distance was significantly longer $(p \leq 0.01)$, while in the final and the third place playoff it was again shorter, although non-significantly. Individually, the longest total distance in a match, i.e. $13.25 \mathrm{~km}$, was covered by an Australian midfielder in the third match of the group stage.

Percentage of total distance covered with high intensity

The mean distance covered by players at high intensity $(19.9-25.2 \mathrm{~km} / \mathrm{h})$, expressed as the percentage of the total distance covered, was 8.83 $\pm 2.11 \%$ in all World Cup matches. It was significantly longer between the quarter-finals and the semi-finals $(p \leq 0.01)$. In the semi-finals the percentage values of total distance covered at high intensity were the greatest (Table 1). Individually, the greatest percentage, i.e. $17 \%$, was achieved in the group stage by two midfielders from Australia and Algeria.

\section{Total number and frequency of sprints}

The mean number of performed sprints by the 2014 World Cup players in all matches was $33.25 \pm 10.67$. The variability of the total number of sprints in seven consecutive rounds of matches of the tournament was similar to that of the distance covered at high intensity. The analysis of this variable did not reveal significant differences between the first round of matches in the group stage $(31.88 \pm 11.05)$ and the quarter-finals (32.44 \pm 8.19). In the following round, a significant ( $p \leq$ 0.01 ) increase in the total number of sprints (approximately 7.24 sprints per match) was noted (Figure 2). The greatest number of performed sprints per match was attained individually by a German midfielder (68 sprints), i.e. one sprint every $82 \mathrm{~s}$ in a semi-final match, while, on the average, the other 2014 World Cup players performed sprints every $173 \mathrm{~s}$.

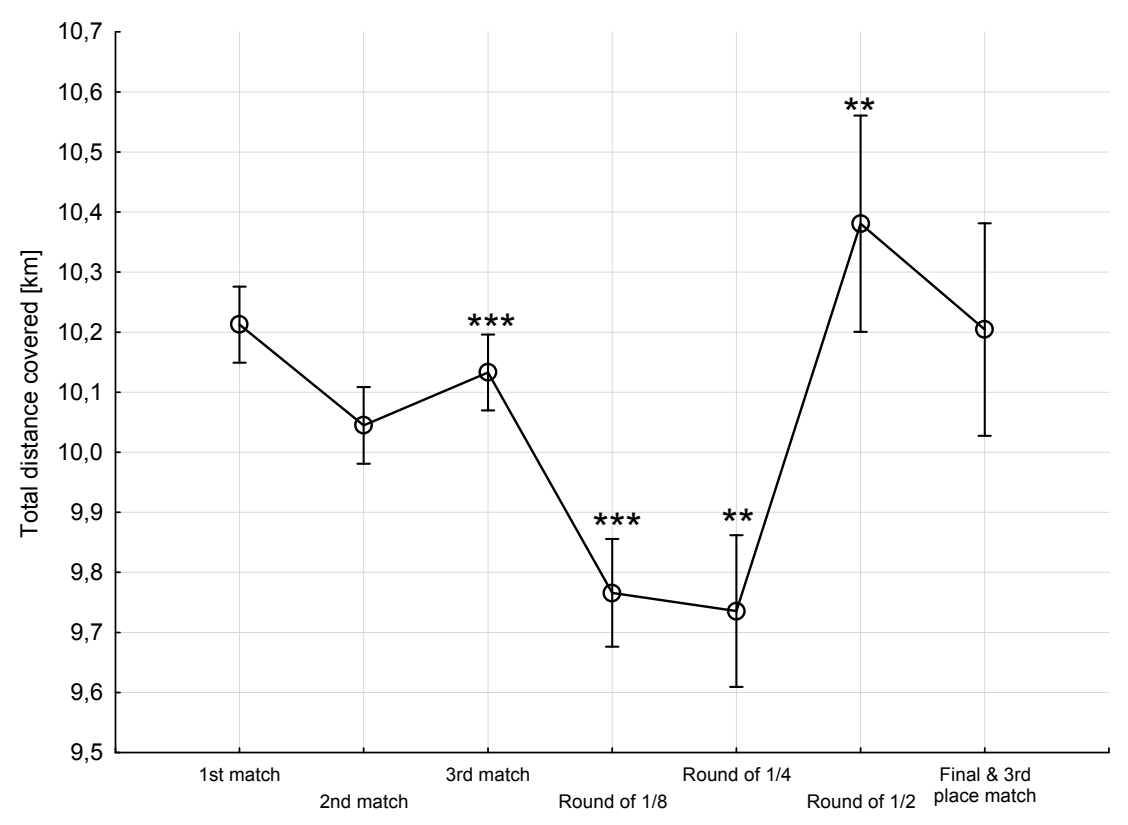

Figure 1

Total distance covered in seven consecutive rounds of matches of the 2014 World Cup in Brazil

Statistically significant differences:

${ }^{*}(p \leq 0.05) ;{ }^{* *}(p \leq 0.01) ;{ }^{* * *}(p \leq 0.001)$ 
Table 1

Mean values of examined variables in seven consecutive rounds of matches of the 2014 World Cup in Brazil

\begin{tabular}{|c|c|c|c|c|c|c|c|}
\hline Variable & 1st match & 2nd match & 3rd match & $\begin{array}{c}\text { Round } \\
\text { of } 16\end{array}$ & $\begin{array}{l}\text { Quarter- } \\
\text { finals }\end{array}$ & Semi-finals & $\begin{array}{l}\text { Final \& 3rd } \\
\text { place match }\end{array}$ \\
\hline & \multicolumn{7}{|c|}{$x \pm S D$} \\
\hline $\begin{array}{c}\text { Distance } \\
\text { covered } \\
\text { at high intensity } \\
{[\%]} \\
\end{array}$ & $8.85 \pm 2.21$ & $8.81 \pm 2.14$ & $8.93 \pm 2.11$ & $8.52 \pm 1.92$ & $8.40^{* *} \pm 1.70$ & $9.86^{* *} \pm 2.45$ & $9.03 \pm 1.99$ \\
\hline $\begin{array}{l}\text { Peak running } \\
\text { speed }[\mathrm{km} / \mathrm{h}]\end{array}$ & $27.66^{*} \pm 2.32$ & $28.16^{*} \pm 2.26$ & $28.16 \pm 2.01$ & $27.88 \pm 2.08$ & $28.27 \pm 2.12$ & $27.82 \pm 2.29$ & $28.50 \pm 1.82$ \\
\hline \multicolumn{8}{|c|}{$\begin{array}{l}\text { Statistically significant differences: } \\
*(p \leq 0.05) ; * *(p \leq 0.01) ; * * *(p \leq 0.001)\end{array}$} \\
\hline
\end{tabular}

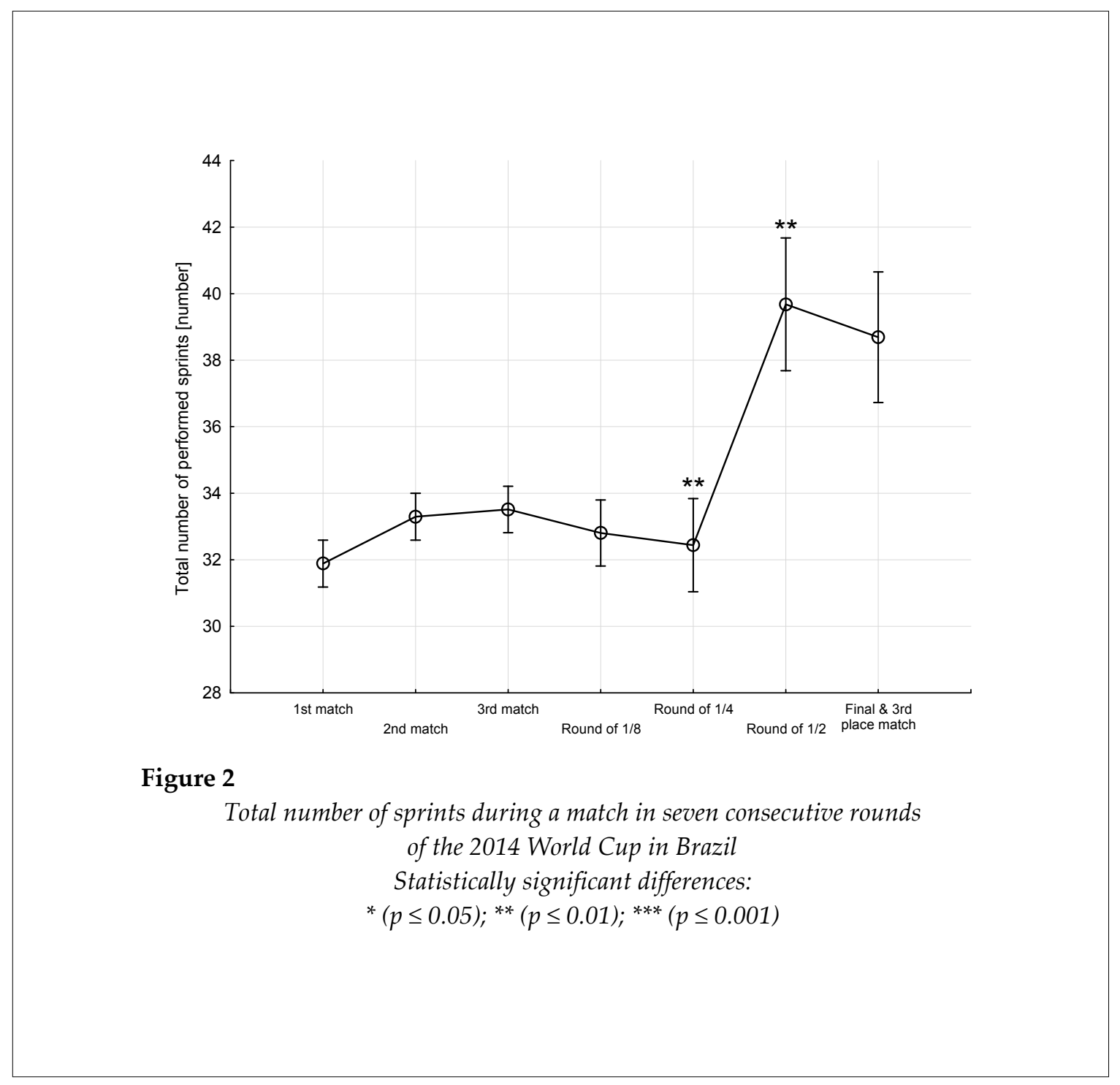




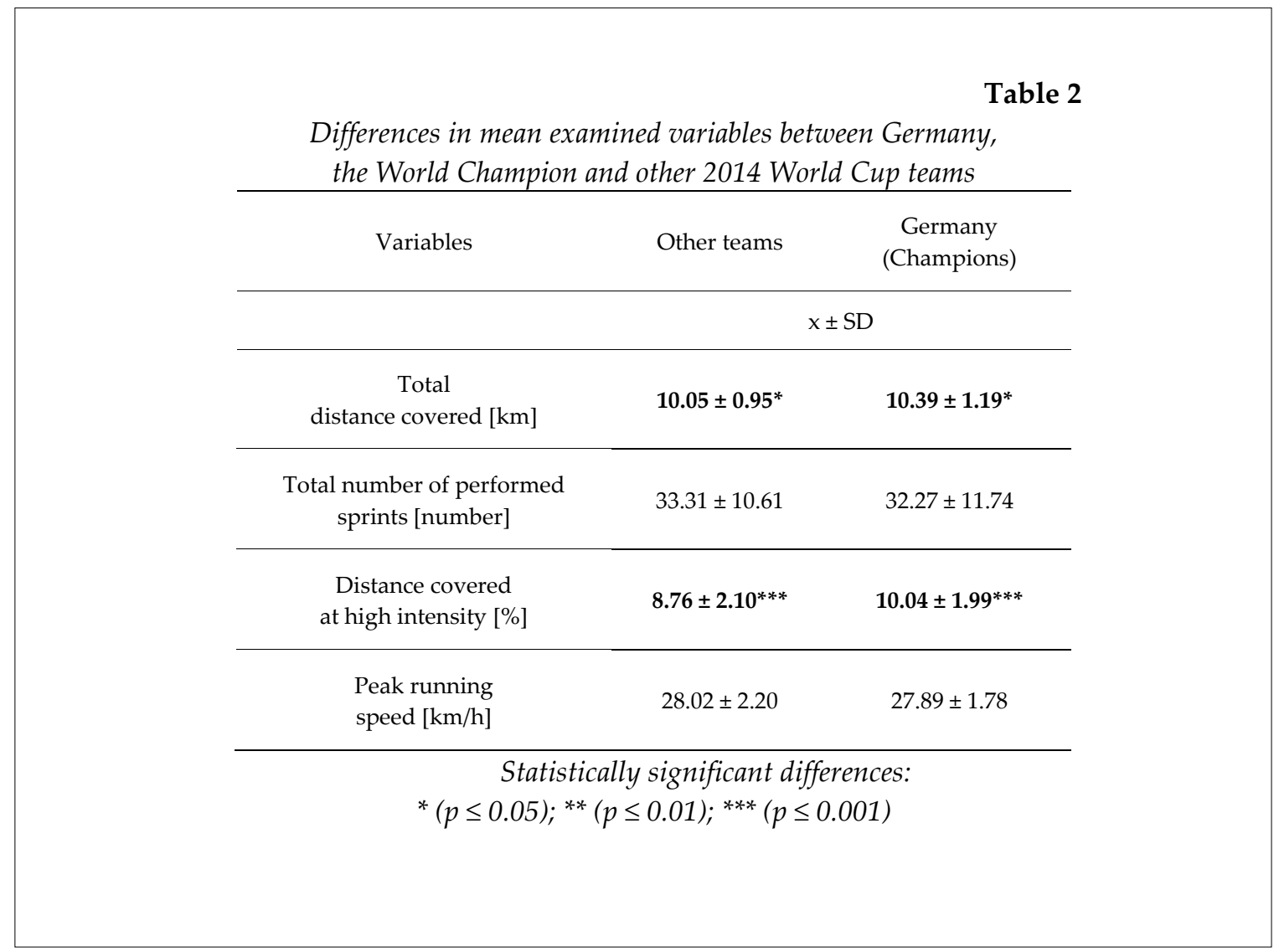

\section{Peak running speed}

The mean peak running speed of the 2014 World Cup players equaled to $28.01 \pm 2.18 \mathrm{~km} / \mathrm{h}$. The results of the present study showed a significant increase in peak running speed between the first and the second rounds of matches of the group stage $(p \leq 0.05)$. In the following rounds the mean peak running speed was relatively stable. The highest peak speed was recorded in the final and the third place match (Table 1). Individually, the greatest peak running speed of the tournament was reached by an Ivory Coast defender, $33.52 \mathrm{~km} / \mathrm{h}$, in the second match of the group stage.

\section{Comparison of the champion Germany team and other World Cup teams}

Significant differences were found in the total distance covered and the distance covered at high intensity between the German players and players from the remaining World Cup teams. The German players covered a significantly longer distance in each match (approximately 340 $\mathrm{m})$ than other players in the tournament $(p \leq 0.05)$. The distance covered at high intensity by the
German players was $1.28 \%$ longer than by other World Cup players $(p \leq 0.001)$. No significant differences were found in the total number of performed sprints and in peak running speed.

\section{Discussion}

The study showed that the total distance covered by players per match decreased significantly between the third round of the group stage and the Round of 16 . Also the total distance covered, the percentage of distance covered at high intensity and total number of sprints increased significantly between the quarter-finals and the semi-finals. The world champions, i.e. the German national team, covered a significantly longer distance and attained a higher percentage of total distance covered at high intensity than the remaining players.

According to Andrzejewski et al. (2014) soccer players can maintain the length of the covered distance at the same level for three consecutive matches in a seven-day macrocycle. A significant reduction in the total distance covered by players between the last match of the group stage and the Round of $16(0.36 \mathrm{~km})$, may be due 
to increased fatigue. The high frequency of World Cup matches together with players' loading after their league seasons do not permit complete recovery (Fowler et al., 2014). The players' fitness may also be affected by environmental conditions (Hue, 2011; Mohr et al., 2010). High air temperature (e.g. $33^{\circ} \mathrm{C}$ in Natal, $31^{\circ} \mathrm{C}$ in Cuiaba) and humidity (e.g. $92 \%$ in Fortaleza, $88 \%$ in Manaus) contribute to disturbances in players' water and electrolyte balance and to higher energy expenditure (Edwards and Noakes, 2009; Fowler et al., 2014; Kurdak et al., 2010).

It is interesting that despite incremental fatigue observed in players in consecutive rounds of the World Cup tournament, a significant increase in total distance covered was noted between the quarter-finals and the semi-finals. It may be explained by the fact that this tournament stage is reached by players who are physically best prepared, resistant to fatigue and equipped with top-level soccer-specific skills. Studies have shown that the distance covered by players in a match is highly correlated with $\mathrm{VO}_{2 \max }$ expressed in $\mathrm{ml} / \mathrm{kg} / \mathrm{min}$ (Hoff and Helgerud, 2004; Metaxas et al., 2006). From the physiological and practical points of view, a greater aerobic capacity allows players not only to cover a longer total distance during a game, perform more sprints, but also to develop better playing dynamics and maintain it for a much longer time during the game (Bangsbo and Krustrup, 2009; Gharbi et al., 2015; Metaxas et al., 2006). This is clearly confirmed by the results of the present studies regarding the distance covered at high intensity and total number of sprints. Improving a players' fitness level while preparing for top ranked sport tournaments in team sport games significantly increases resistance to fatigue and induces greater match load tolerance. Increased aerobic capacity also improves recovery during rest periods in match play and in parts of low intensity activities (Bangsbo, 1994; Mohr et al., 2010). High aerobic capacity also affects the attainment of the psychomotor fatigue threshold during match performance of high intensity (Chmura et al., 2010; Oh et al., 2011).

The match strategy for a tournament lasting a few weeks is to ensure a satisfactory level of players' fitness allowing their team to advance to the knockout stage, and to maintain the highest fitness level for the final rounds of the tournament. This is confirmed in the present study by the measurements of peak running speed between the first and the second rounds of the group stage, and by the highest peak running speed recorded during the third place match and the final. The very high and relatively stable value of peak running speed in the consecutive rounds of the 2014 World Cup was, on average, $2.5 \mathrm{~km} / \mathrm{h}$ higher than during the 2010 World Cup in South Africa (Oh et al., 2011). Maintaining a high level of peak running speed in the knockout stage is most likely caused by the high rank of the tournament. Playing matches against better opponents and the risk of dropping out of the tournament generate strong motivation in players (Payne et al., 2013). It must be noted that even the slightest decrease in peak running speed, compared to the opponent, may lead to a ball loss and, in consequence, to losing a goal and a match (Yue et al., 2014).

There has been steady progress in players' conditioning. During a high-level soccer match, a player performs a sprint every four minutes on the average (Reilly et al., 2008). The higher frequency of sprints (every $2 \mathrm{~min}$ and $53 \mathrm{~s}$ on the average, and individual player's record for every 82 s) in the present study points to increasing game dynamics in modern soccer. Considering the best individual players' results in the present study, a question can be posed whether it is possible for a player to cover a total distance of $13.25 \mathrm{~km}$, including $17 \%$ at high intensity (above $19.9 \mathrm{~km} / \mathrm{h}$ ), perform 68 sprints (one sprint every $82 \mathrm{~s}$ ), and reach peak running speed of 33.52 $\mathrm{km} / \mathrm{h}$ ? Efficient $V_{2}$ max, anaerobic threshold intensity, exercise economy and ability to repeat anaerobic exercises may contribute to achieving this objective (Chmura et al., 2015). It may be possible with an appropriate players' genotype, training loads control and strict cooperation between coaches and scientists.

The World Champions, the German national team, indeed featured a significantly longer total distance covered and distance covered at high intensity in match play than other teams of the 2014 World Cup in Brazil. The high levels of these variables had a great effect on the German team's top standing during the last Word Cup. Moreover, the total distance covered by the German team in their seven 2010 World Cup matches collectively was $758.81 \mathrm{~km}$, while in 2014 it was $768.39 \mathrm{~km}$, i.e. $9.58 \mathrm{~km}$ longer (unpublished 
data). The analysis of motor activities of the German soccer players allows to establish a set of standards of motor skills to be pursued by other soccer teams (Chmura et al., 2014) and to improve the development of soccer worldwide.

\section{Practical implications}

Updated kinematic information on soccer players taking part in World Cup matches is highly significant for sport practice. The collected data may have significant implications for conditioning of elite soccer players. After a long and exhaustive competitive season, preparing for top-level tournaments must account for repetitive high-intensity exercises. Performance of sprints every 82 seconds on average, as well as application of training means aimed at developing peak running speed are particularly recommended. A high level of aerobic capacity seems necessary to implement such training loads.

\section{Conclusions}

A significant increase in total distance covered, distance covered at high intensity, and total number of sprints in a match in the semifinals of the 2014 World Cup in Brazil is noticeable. It is an indication of the high demands of players' speed and endurance abilities necessary for their motor activities in the key rounds of top-level soccer tournaments. Winning a top ranked soccer tournament requires players to cover longer mean total distances as well as longer distances at high intensity during a match. This implies that elite soccer players must possess high levels of aerobic capacity. The preparation process for top-level soccer competitions must specifically account for the development of players' endurance and speed-endurance abilities.

\section{References}

Andrzejewski M, Konarski J, Chmura J, Pluta B. Changes in the activity profiles of soccer players over a three-match training micro cycle. Int J Perform Anal Sport, 2014; 14: 814-828

Andrzejewski M, Chmura J, Pluta B, Strzelczyk R, Kasprzak A. Analysis of sprinting activities of professional soccer players. J Strength Cond Res, 2013; 27: 2134-40

Bangsbo J. The physiology of soccer: With special reference to intense intermittent exercise. Acta Physiol Scand, 1994; 151: 1-155

Bangsbo J, Krustrup P. Physical demands and training of top-class soccer players. In: T. Reilly and F. Korkusuz (eds.) Science and Football VI. New York: Routledge, 318-330; 2009

Bishop DJ, Girard O. Determinants of team-sport performance: implications for altitude training by teamsport athletes. Br J Sport Med, 2013; 47: 17-21

Bradley PS, Sheldon BJ, Wooster B, Olsen P, Boanas P, Krustrup P. High-intensity running in English FA Premier League soccer matches. J Sports Sci, 2009; 27: 159-168

Chmura J, Nazar K. Parallel changes in the onset of blood lactate accumulation (OBLA) and threshold of psychomotor performance deterioration during incremental exercise after training in athletes. Int $J$ Psychophysiol, 2010; 75: 287-90

Chmura P, Goliński D, Andrzejewski M, Mroczek D, Kawczyński A, Rokita A, Chmura J. Endurance capacity and selected technical-tactical skills of soccer players participating in the group stage of the 2014 FIFA World Cup. Trends Sport Sci, 2014; 3: 153-160

Chmura P, Konefał M, Kowalczuk E, Andrzejewski M, Rokita A, Chmura J. Distances Covered above and below the Anaerobic Threshold by Professional Football Players in Different Competitive Conditions. Cent Eur J Sport Sci Med, 2015; 10: 25-31

Dellal A, Wong DP, Moalla W, Chamari K. Physical and technical activity of soccer players in the French First League: With special reference to their playing position. Int SportMed J, 2010; 11: 278-290

Dellal A, Chamari C, Wong DP, Ahmaidi S, Keller D, Barros MLR, Bisciotti GN, Carling C. Comparison of physical and technical performance in European professional soccer match-play: The FA Premier League and La LIGA. Eur J Sport Sci, 2011; 11: 51-59

Djaoui L, Wong del P, Pialoux V, Hautier C, Da Silva CD, Chamari K, Dellal A. Physical Activity during a 
Prolonged Congested Period in a Top-Class European Football Team. Asian J Sports Med, 2014; 5: 47-53

Di Salvo V, Baron R, Tschan H, Calderon Montero FJ, Bachl N, Pigozzi F. Performance characteristics according to playing position in elite soccer. Int J Sports Med, 2007; 28: 222-7

Di Salvo V, Gregson W, Atkinson G, Tordoff P, Drust B. Analysis of high intensity activity in Premier League soccer. Int J Sports Med, 2009; 30: 205-212

Edwards AM, Noakes TD. Dehydration: cause of fatigue or sign of pacing in elite soccer? Sports Med, 2009; 39: $1-13$

Fowler P, Duffield R, Vaile J. Effects of domestic air travel on technical and tactical performance and recovery in soccer. Int J Sports Physiol Perform, 2014; 9: 378-86

Hoff J, Helgerud J. Endurance and Strength Training for Soccer Players - Physiological Considerations. Sports Med, 2004; 34: 165-180

Hue O. The challenge of performing aerobic exercise in tropical environments: applied knowledge and perspectives. Int J Sports Physiol Perform, 2011; 6: 443-54

Gharbi Z, Dardouri W, Haj-Sassi R, Chamari K, Souissi N. Aerobic and anaerobic determinants of repeated sprint ability in team sports athletes. Biol Sport, 2015; 32: 207-12

Konefał M, Chmura P, Andrzejewski M, Chmura J. Analysis of motor performance of professional soccer players in different environmental conditions. Trends Sport Sci, 2014; 4: 221-227

Kurdak SS, Shirreffs SM, Maughan RJ, Ozgünen KT, Zeren C, Korkmaz S, Yazici Z, Ersöz G, Binnet MS, Dvorak J. Hydration and sweating responses to hot-weather football competition. Scand J Med Sci Sports, 2010; 20: 133-9

Metaxas T, Sendelides T, Koutlianos N, Mandroukas K. Seasonal variation of aerobic performance in soccer players according to positional role. J Sports Med Phys Fitness, 2006; 46: 520-5

Mohr M, Krustrup P, Bangsbo J. Match performance of high-standard soccer players with special reference to development of fatigue. J Sports Sci, 2003; 21: 519-28

Mohr M, Mujika I, Santisteban J, Randers MB, Bischoff R, Solano R, Hewitt A, Zubillaga A, Peltola E, Krustrup P. Examination of fatigue development in elite soccer in a hot environment: a multiexperimental approach. Scand J Med Sci Sports, 2010; 20: 125-32

Oh Sang Duk, Kim Sung Min, Kawczyński A, Chmura P, Mroczek D, Chmura J. Endurance and speed capacity of the Korea Republic football national team during the World Cup of 2010. J Hum Kinet, 2011; 30: 93-106

Payne SM, Hudson J, Akehurst S, Ntoumanis N. Development and initial validation of the Impression Motivation in Sport Questionnaire-Team. J Sport Exerc Psychol, 2013; 35: 281-98

Reilly T. Motion analysis and physiological demands. In: T. Reilly and AM. Williams (eds.) Science and Soccer: London: E \& FN Spon, 9-72; 2003

Reilly T, Drust B, Clarke N. Muscle Fatigue during Football Match-Play Sports Med, 2008; 38: 357-367

Soroka A. The locomotor activity of football players based on playing positions during the 2010 World Cup. J Sports Med Phys Fitness, 2014; Epub Ahead of print

Spencer M, Bishop D, Dawson B, Goodman C. Physiological and metabolic responses of repeated-sprint activities. Sports Med, 2005; 35: 1025-1044

Yue Z, Broich H, Mester J. Statistical Analysis for the Soccer Matches of the First Bundesliga. Int J Sports Sci Coach, 2014; 9: 553-560

\section{Corresponding author:}

\section{Pawel Chmura}

Chair of Team Sports, University School of Physical Education in Wrocław

al. I.J. Paderewskiego 35 , 51-612 Wrocław, Poland

Phone: +48713473564; Fax: +48713473561;

E-mail: pawel.chmura@awf.wroc.pl 